\title{
PERANCANGAN PENATAAN SENTRA KULINER DAN TOILET UMUM DI TAMAN KOTA DENPASAR
}

\author{
I Made Juniastra \\ Program Study Teknik Industri, Fakultas Teknik, Universitas Mahendradatta \\ JI. Ken Arok No. 12 Peguyangan, Denpasar, Bali 80115 \\ Email : juniastra@gmail.com
}

\begin{abstract}
Abstrak - Taman Kota Denpasar atau yang lebih umum disebut Lapangan Lumintang memang menjadi pusat rekreasi dan olahraga di Kota Denpasar. Letaknya yang strategis di pusat permukiman dan perkantoran dan di pinggir jalan utama (Jl. Gatot Subroto) menyebabkan aktivitas di taman kota menjadi sangat ramai. Demikian juga keberadaan lapangan umum di sebelah selatan, Art Centre Darma Negara Alaya di sebelah barat, dan Pura Agung Lokanatha Denpasar di sudut timur laut taman kota menegaskan pentingnya keberadaan taman kota menjadi pusat orientasi kawasan. Keberadaan area kuliner dan toilet umum tentu sangat penting untuk menunjang fungsi taman kota dan fasilitas publik lain di sekitarnya. Keberadaan area kuliner dan toilet umum sekarang terletak di lereng sungai yaitu sebelah selatan pura dan tepat di samping panggung seni terbuka, sehingga mengganggu pemandangan dan kebersihan dari taman kota. Penataan zonasi ruang, pencahayaan dan penghawaan, sirkulasi pencapaian, serta struktur menjadi titik penting dari perancangan agar bisa mewadahi fungsinya dan menunjang keindahan taman kota. Perancangan penataan dilakukan dengan memanfaatkan potensi site di pinggir sungai dengan kondisi berlereng. Bangunan direncanakan bertingkat kebawah. Area kuliner dan public toilet diletakkan di lantai bawah (basement) dan lantai atas berupa pelat beton menjadi bersih dan terbuka untuk dijadikan lapangan dan taman hijau. Demikian juga keberadaan sungai menjadi sisi depan dari area kuliner sehingga otomatis akan lebih terjaga kebersihannya.
\end{abstract}

Kata kunci : Perancangan; Industri Kuliner; toilet umum; taman kota

Abstract - Denpasar City Park or more commonly called Lumintang Field is indeed a recreation and sports center in Denpasar City. Its strategic location in the center of settlements and offices and on the side of the main road (Gatot Subroto road) causes activity in city parks to be very busy. Likewise, the existence of a public square in the south, the Art Center Darma Negara Alaya in the west, and Agung Lokanatha Denpasar Temple in the northeast corner of the city park emphasizes the importance of city parks being the center of regional orientation. The existence of a culinary area and public toilets is of course very important to support the function of city parks and other public facilities around it. The culinary area and public toilets are now located on the river slopes south of the temple and right next to an open art stage, thus disturbing the view and cleanliness of the city park. Arrangement of space zoning, lighting and ventilation, circulation of achievement, and structure are important points of design in order to accommodate their functions and support the beauty of city parks. The arrangement design is carried out by utilizing the potential sites on the river bank with sloping conditions. The building is planned to be terraced down. The culinary area and public toilets are placed on the basement and the upper floor in the form of concrete slabs, which are clean and open to become a green field and garden. Likewise, the river is the front side of the culinary area so that it will automatically be more clean.

Key words: Design; Culinary Industry; public toilet; City Park

\section{PENDAHULUAN}

Taman kota Denpasar terletak pada lokasi yang sangat strategis, yaitu di pinggir jalan utama (Jl. Gatot Subroto Timur) yang menghubungkan Jawa - Bali - Lombok. Disamping itu Taman
Kota Denpasar juga terletak di tengah-tengah permukiman penduduk, yang dikelilingi oleh perkantoran, Lapangan Lumintang, Art Centre Kota Denpasar Dharma Negara Alaya, Dan Juga Pura Agung Lokanatha Denpasar Taman Kota Denpasar juga memiliki panggung kreasi terbuka 
yang dilengkapi audio visual dan fasilitas duduk yang nyaman. Masyarakat sangat ramai beraktivitas di Taman Kota Denpasar, ada yang bertujuan olahraga, duduk bercengkrama bersama keluarga sambil menghirup udara segar, berkumpul dengan komunitas mengadakan kegiatan bersama, sembahyang ke pura, ataupun sekedar berhenti sejenak dari perjalanan sambil menikmati kuliner yang dijual di sentra kuliner yang ada di sana. Meskipun secara kesehatan, kondisi area kuliner disana sudah cukup bersih dan higienis, tapi dari segi visual masih perlu dilakukan penataan, karena letaknya yang di pinggir lintasan jogging track, di samping panggung terbuka, dan di pinggir pura. Area kuliner yang menjadi satu dengan toilet umum ini merupakan jalur sirkulasi area timur taman kota, dan dari segi visual menghalangi view positif ke pura dan ke sungai di bawahnya.

Area kuliner yang ada di Taman Kota Denpasar seluruhnya menjual kuliner. Keberadaan area kuliner ini merupakan daya tarik tersendiri bagi taman kota sehingga keberadaannya perlu dilestarikan dan ditata supaya menjadi unsur penunjang positif bagi taman kota itu sendiri.

“... Ada dugaan kuat bahwa pedagang kaki lima masih dan akan tetap dibutuhkan oleh masyarakat kota, lagipula sesuai dengan kekhasan masyarakat Indonesia yang konon memiliki outdoor personality, kesempatan tawar menawar di udara terbuka merupakan kenikmatan tersendiri. Sama halnya dengan berkelakar pada malam hari di gardu ronda atau berdesas-desus di MCK" (Eko Budiharjo).

Dengan demikian maka diperlukan suatu pemikiran untuk menata area kuliner dan toilet umum tersebut tanpa mengganggu aktivitas pengunjung Taman Kota Denpasar dengan memanfaatkan potensi site yang ada.

\section{METODE PENELITIAN}

\section{Studi Literatur}

Mencari informasi dan literatur di media elektronik ataupun media cetak mengenai sentra kuliner dan toilet umum, taman kota dan ruang terbuka umum, Analisa dan konsep arsitektur dan hal-hal yang terkait penataan taman kota dan toilet umum.

\section{Observasi}

Kunjungan langsung ke site mengenai situasi eksisting area kuliner dan toilet umum, untuk mendata dan mengetahui kondisi fisik lokasi, jumlah pedagang, kondisi dan potensi site, view positif, harapan Pemerintah Kota, harapanharapan pedagang dan masyarakat pengguna Taman Kota Denpasar, dan informasi lain yang baru akan terlihat kalau sudah berada langsung di site.

\section{Analisa}

Setelah data di kumpulkan baik dengan cara study literatur ataupun dengan observasi langsung, maka data dikelompokkan sesuai dengan kaidah-kaidah perencanaan arsitektur, sehingga situasi positif dan negative dari site dan pola hubungannya akan terlihat dengan jelas. Data-data utama yang didapat dari pengumpulan data tersebut adalah kondisi dan potensi site, jumlah pedagang beserta kebutuhan peralatan untuk aktivitas berjualan, harapan pemerintah kota, dan harapan pedagang serta pengunjung taman kota. Dari data dan tujuan tersebut dibuat beberapa analisa alternative perencanaan yang mungkin bisa diterapkan dengan baik.

\section{Kosep}

Setelah melalui tahapan analisa arsitektur, maka ditetapkan konsep-konsep yang akan diterapkan dalam perancangan. Konsep penzoningan ruang, konsep sirkulasi, konsep view dan orientasi, konsep pencahayaan dan penghawaan, konsep struktur, dan konsep lainnya yang saling terkait satu sama lainnya. Konsep tersebut dituangkan kedalam gambar perencanaan dengan skala yang terukur.

\section{HASIL DAN PEMBAHASAN Analisa Dan Konsep Tapak}

Site berada di sisi timur taman kota. Di sebelah utaranya adalah pura dan disebelah selatan adalah panggung terbuka kreativitas anak muda. Kondisi site adalah berkontur tajam /berlereng dengan ketinggian $\pm 4,5$ meter. Pedagang kaki lima di sebelah timur menjadi satu komplek dengan toilet umum di sebelah barat. Toilet umum berada di level atas, dan area kuliner di 
lereng dengan penataan eksisting adalah berundak ke bawah. Di level bawah site adalah oleh pemerintah kota dan bisa dijadikan tempat sungai yang tepi nya sudah tertata dengan baik
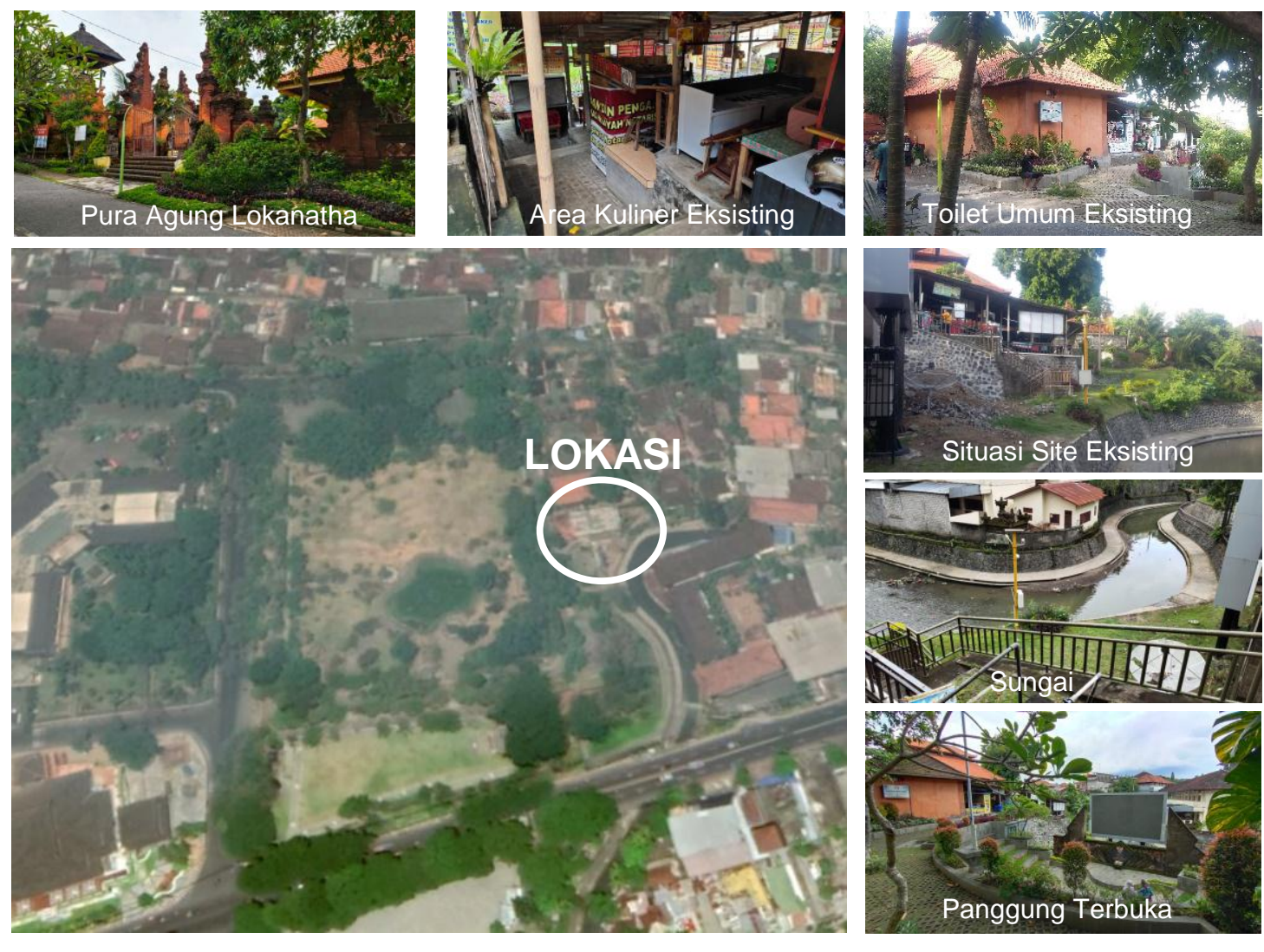

Gambar 1. Foto Site Eksisting
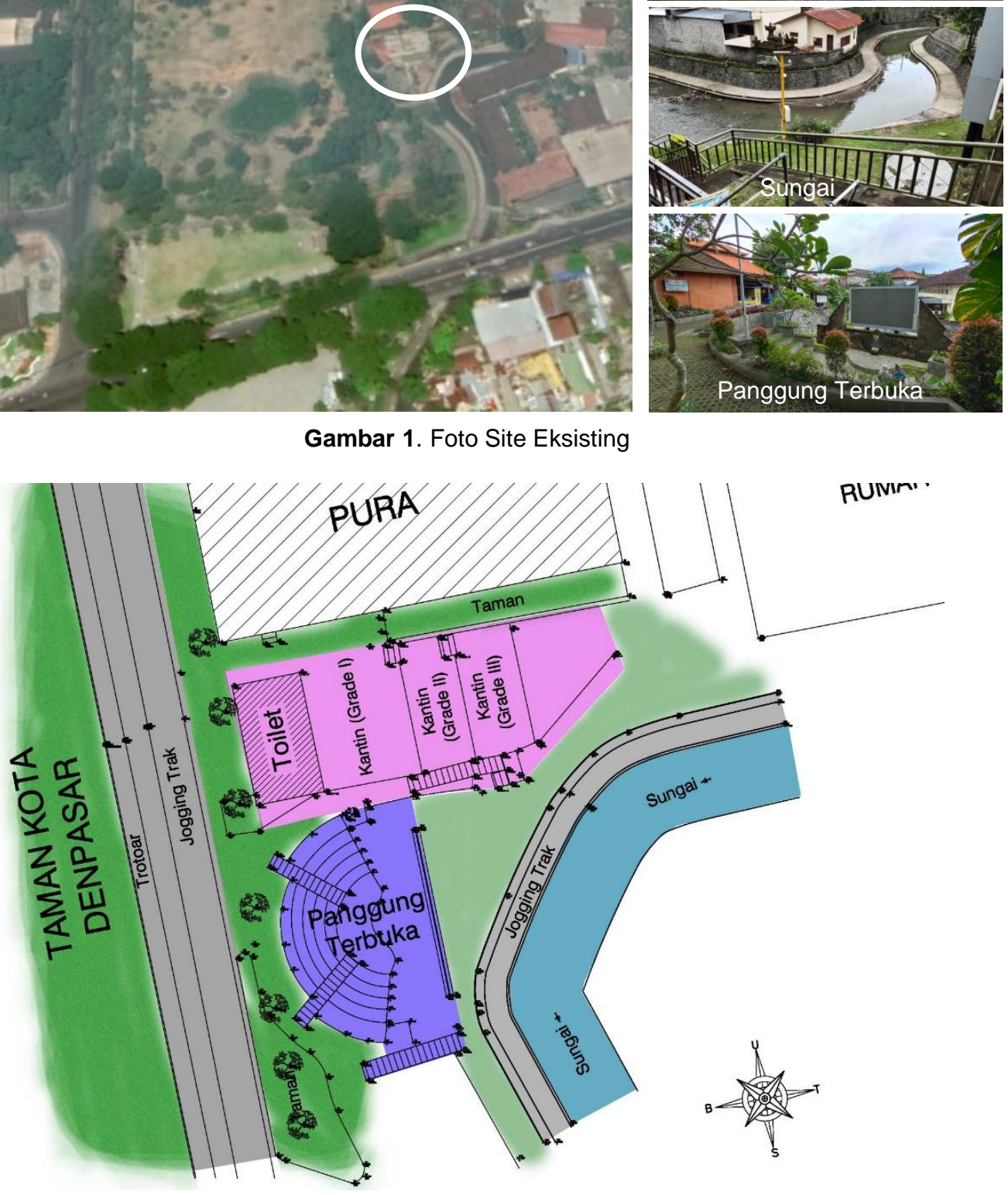

Gambar 2. Gambar Site Eksisting 
Konsep penataan tapak adalah membagi site menjadi dua, yaitu level atas dan level bawah. Level atas sejajar dengan taman kota, dan level bawah sejajar dengan kebun bawah serta sungai. Untuk level atas di gunakan untuk kebun /taman terbuka dengan plater box berisi tanaman. Ini selaras dengan kebijakan pemerintah yaitu untuk fungsi taman kota. View di level atas menjadi view positif ke segala arah. Keberadaan Pura menjadi terlihat dengan jelas dari arah selatan (arah jalan raya). Taman ini sekaliigus bisa menjadi zona perantara antara pura dengan taman kota sehingga masyarakat di taman kota dan masyarakat yang sembahyang di pura mempunyai priivasi yang cukup baik.

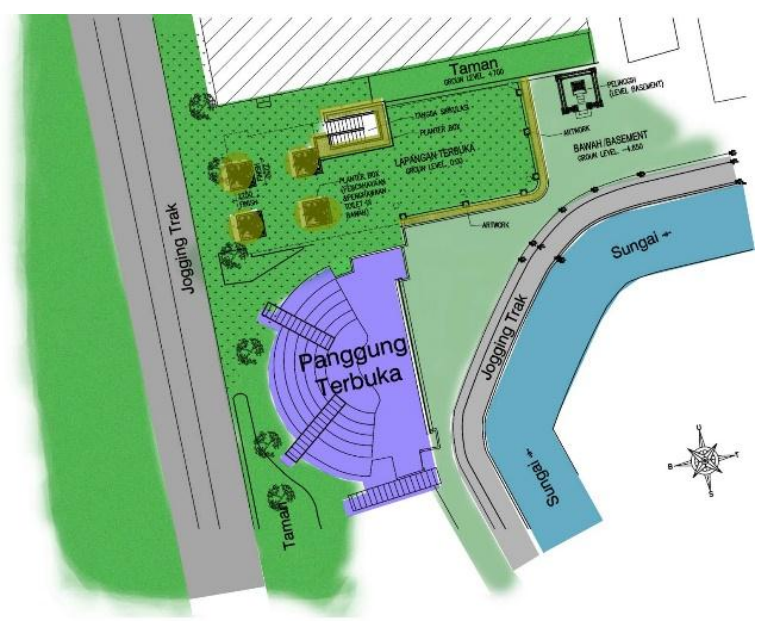

Gambar 3. Rencana Layout Level Atas

\section{Analisis Dan Konsep Pelaku, Aktivitas Dan Besaran Ruang}

Berdasarkan hasil survey dan observasi lapangan, bisa terdata ruang ruang yang diperlukan antara lain:

- Tangga sirkulasi

- Foyer

- Toilet umum laki-laki

- Toilet umum perempuan

- Toilet umum orang suci (sulinggih /pendeta)

- Wastafel umum

- Area sewa sentra kuliner /tenant

- Meja makan
Sedangkan untuk fungsi sentra kuliner dan toilet umum di pindahkan ke level bawah (basement) dengan posisi masih tetap di tempat semula. Toilet umum tidak membutuhkan view sehingga bisa ditempatkan di sisi dalam (sebelah barat) dan tempat makan ditempatkan di sisi luar dengan view positif terbuka ke arah kebun bawah dan pemandangan sungai.

Konsep massa bangunan berupa satu buah massa bangunan tunggal dengan proses pembentukan site berupa cut and fill dengan pertimbangan desain struktur dinding penahan tanah (retaining wall) beton bertulang dengan kualitas yang didesain kedap air.

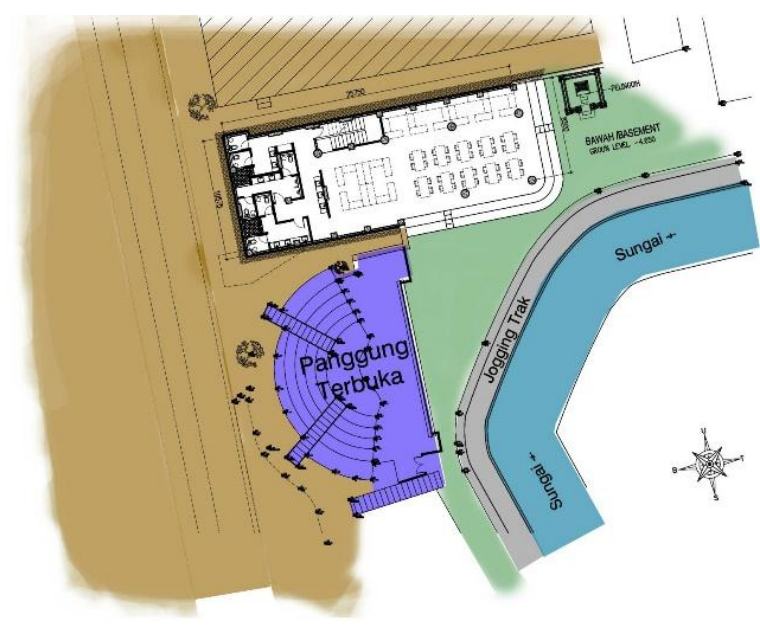

Gambar 4. Rencana Layout Level Bawah (Basement)

Masing-masing pelaku di identitaskan sesuai dengan fungsi dan aktivitasnya di dalam bangunan. Kemudian dari aktivitas tersebut bisa ditentukan kebutuhan ruangnya secara lebih spesifik. Kemudian langkah selanjutnya adalah menentukan faktorial dari kebutuhan ruang agar bisa ditentukan bentuk awal massa bangunan. Analisis ini berpedoman pada data dan literatur yang didapat saat pengumpulan data dengan kebijakan dan masukan dari Pemerintah Kota Denpasar dan dikomparasi dengan literaturliteratur yang sesuai.

Dari hasil pengumpulan data melalui interview langsung dan beberapa literatur, diperoleh ruang 
ruang yang diperlukan beserta fungsi dan ukurannya yang tersaji dalam tabel berikut ini:

Tabel 1. Analis Pelaku, Aktivitas, Dan Besaran Ruang

\begin{tabular}{|c|c|c|c|c|c|}
\hline No & Nama Ruangan & Fungsi & Jumlah & $\begin{array}{l}\text { Kebutuhan } \\
\text { Ruang }\end{array}$ & $\begin{array}{l}\text { Faktorial } \\
\text { Ruang }\end{array}$ \\
\hline 1 & Tangga & Sirkulasi & & \multicolumn{2}{|c|}{ Varies } \\
\hline 2 & Foyer & $\begin{array}{l}\text { Ruang perantara antara } \\
\text { tangga dengan fasilitas } \\
\text { ruang lantai bawah } \\
\text { /basement }\end{array}$ & 1 & $9 \mathrm{M}^{2}$ & $1,5 \times 6 \mathrm{M}^{2}$ \\
\hline 3 & $\begin{array}{l}\text { Toilet Umum Laki- } \\
\text { laki }\end{array}$ & $\begin{array}{l}\text { MCK dan ruang ganti } \\
\text { pengunjung laki-laki }\end{array}$ & 1 set & $18 M^{2}$ & Varies \\
\hline 4 & $\begin{array}{l}\text { Toilet Umum } \\
\text { Perempuan }\end{array}$ & $\begin{array}{l}\text { MCK dan ruang ganti } \\
\text { pengunjung perempuan }\end{array}$ & 1 set & $18 \mathrm{M}^{2}$ & Varies \\
\hline 5 & $\begin{array}{l}\text { Toilet Umum } \\
\text { Orang Suci } \\
\text { /Sulinggih }\end{array}$ & $\begin{array}{l}\text { MCK dan ruang ganti } \\
\text { sulinggih /orang suci }\end{array}$ & 1 set & $16 M^{2}$ & Varies \\
\hline 6 & Area Wastafel & $\begin{array}{l}\text { Cuci tangan sebelum } \\
\text { dan sesudah makan }\end{array}$ & 1 & $10 \mathrm{M}^{2}$ & $2 \times 4,5 \mathrm{M}^{2}$ \\
\hline 7 & $\begin{array}{l}\text { Area Sewa } \\
\text { Pedagang Kaki } \\
\text { Lima/Tenant }\end{array}$ & $\begin{array}{l}\text { Menaruh meja display } \\
\text { masakan dan tempat } \\
\text { mengolah makanan }\end{array}$ & $\begin{array}{c}10 \\
\text { tenant }\end{array}$ & $@ 3,75 \mathrm{M}^{2}$ & $1,5 \times 2,5 \mathrm{M}^{2}$ \\
\hline 8 & Meja Makan & $\begin{array}{l}\text { Tempat makan dan } \\
\text { duduk santai }\end{array}$ & $\begin{array}{c}10 \text { set } \\
\text { meja }\end{array}$ & $60 \mathrm{M}^{2}$ & $6 \times 10 \mathrm{M}^{2}$ \\
\hline
\end{tabular}

Sesuai dengan kebutuhan ruang tersebut bisa dkelompokkan sifat ruang public, semi public, dan privat. Langkah selanjutnya adalah menentukan menentukan penzoningan ruang dan urutan aktivitas pelaku. Aktivitas sirkulasi pelaku di dalam tapak dipolakan berdasarkan pola hierarki (konfigurasi ruang), sirkulasi dan aktivitas.

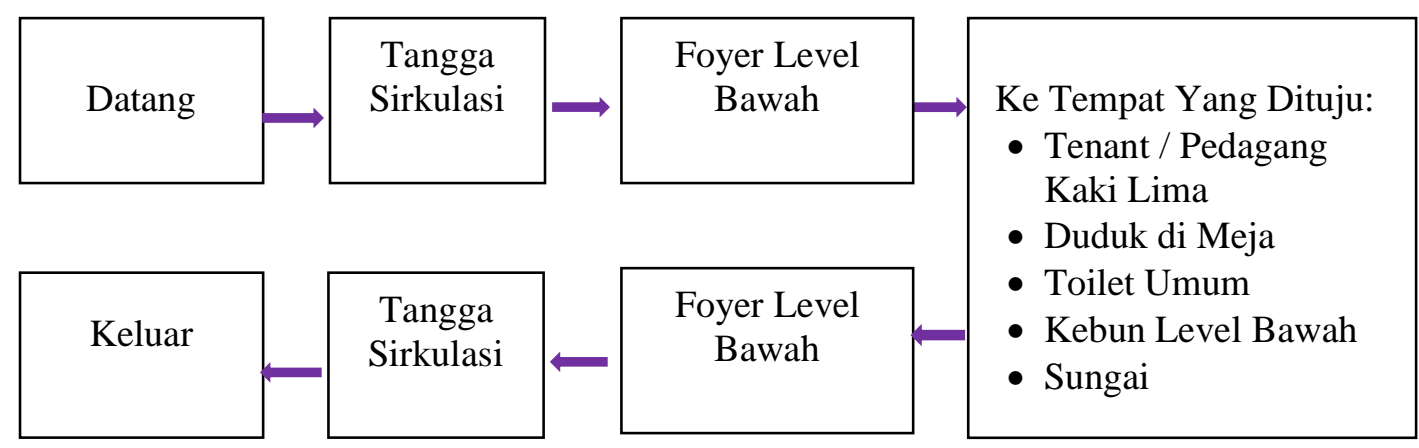

Gambar 5. Diagram Urutan Aktivitas Pedagang Dan Pengunjung

\section{Analisa Dan Konsep Bangunan}

Bangunan terdiri dari massa bangunan tunggal dengan konsep utama adalah mengutamakan taman kota. Sehingga focus perencanaan dan perancangan adalah mengusahakan penempatan taman semaksimal mungkin. Sedangkan penataan sentra kuliner dan toilet umum adalah fasilitas penunjang yang sekaligus sangat penting dan bisa menjadi unsur penunjang keberadaan taman kota.

Bangunan dirancang dengan struktur bertingkat dengan lantai atas yang dirancang rata dengan level tanah taman kota, sehingga akan menyatu setelah ditambah tanah subur dan diisi vegetasi. 
Sedangkan untuk fasilitas sentra kuliner dan toilet umum dibawa ke lantai bawah (basement) dengan view positif kebun bawah dan sungai dengan jogging track.

Penempatan toilet umum dikelompokkan dalam satu zona yaitu di sebelah barat. Toilet umum dikelompokkan menjadi tiga macam, yaitu toilet perempuan, toilet laki-laki, dan toilet orang suci /sulinggih untuk fasilitas penunjang Pura.
Masing-masing toilet diilengkapi dengan dua WC, ruang wastafel, dan urinoir. ruang toilet umum dirancang sedemikian rupa sehingga harmonis satu sama lain dan tetap menjaga privasi antara masing-masing toilet. Masing masing toilet dirancang dengan penghawaan dan pencahayaan alami dengan tetap mempertimbangkan privasi. (gambar 3. dan gambar. 4)

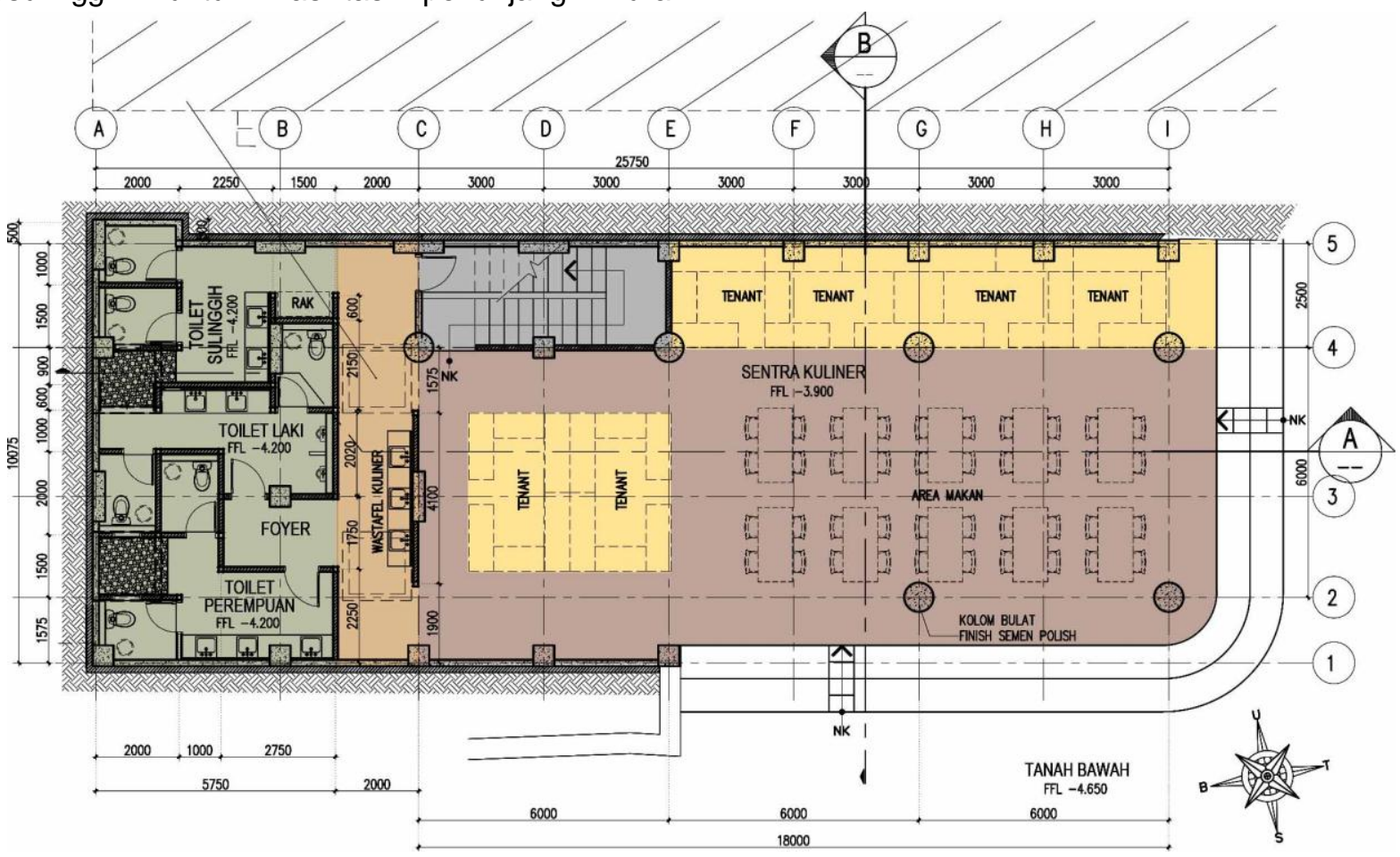

Gambar 6. Denah lantai bawah (basement)

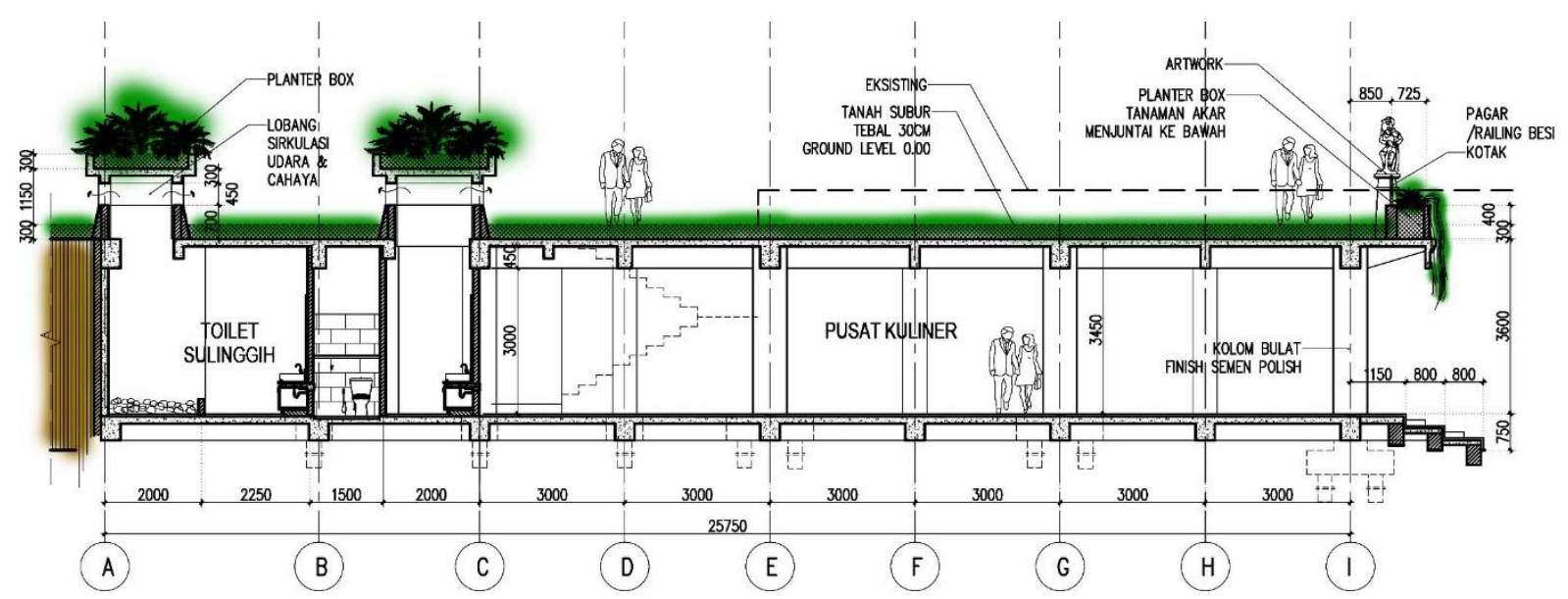

Gambar 7. Potongan A - A

Area tenant /sentra kuliner dirancang dengan jumlah kios sebanyak 10 kios dengan posiisi di sebelah timur dengan view positif kearah kebun dan sungai. Masing-masing kios pedagang dilengkapi fasiltas listrik, air bersih, dan saluran air kotor/bekas. Air kotor/bekas ditampung di 
bak penampungan dan airnya dialirkan ke sumur resapan dan dikontrol secara berkala agar tidak mencemari lingkungan.

Area meja makan letaknya paling diutamakan dengan pertimbangan kenyamanan bersantap pengunjung. Posisinya dengan view paling bagus yaitu dipinggir kebun dan sungai dengan udara segar dari lingkungan. Meja makan dirancang sebanyak 10 buah untuk fasilitas bersama bagi seluruh pedagang. Jadi pengunjung bisa duduk dimana saja dan memesan kuliner dimana saja. Area kuliner ini dilengkapi dengan wastafel dengan fasilitas dan standar kenyamanan yang tiinggi untuk mendukung fungsi kuliiner.

Kolom kolom ekspose menggunakan kolom bulat dengan bentangan $6 \mathrm{~m} \times 6 \mathrm{~m}$ pada area makan dengan tinggi level lantai bawah dengan lantai atas adalah $6 \mathrm{~m}$ agar memberi kesan lega dan nyaman.

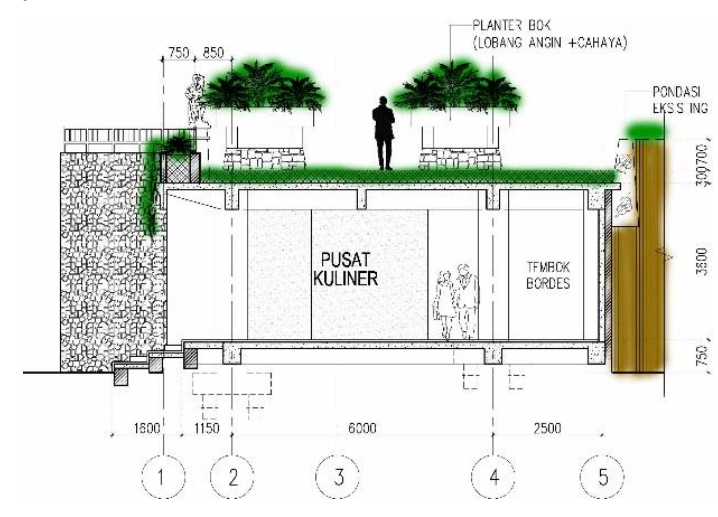

Gambar 8. Potongan B - B

\section{Tinjauan Arsitektur Tradisional Bali}

Konsep penzoningan menerapkan konsep sanga mandala yaitu membagi area menjadi sembilan bagian. pola Tri Mandala, sebagai cerminan atau miniatur Tri Loka (Swah, Bhuah, Bhur loka) selaku tubuh alam semesta. Sumbu utaraselatan yang terdiri dari Utama Mandala, Madya Mandala, Nista Mandala. Sumbu sekunder membujur pada arah timur-barat dimana timur sebagai arah utama, arah matahari terbit sebagai sumber kehidupan sehingga terbentuk struktur 9 kawasan (Sanga Mandala) sebagai wujud keseimbangan alam. Arah timur laut sebagai posisi suci atau utama, dan arah barat daya

\section{Analisa Dan Konsep Struktur}

Karena bangunan berupa setengah basement, maka perencanaan struktur diperhitungkan dengan baik. Dinding yang bersentuhan langsung dengan tanah tegak menggunakan dinding beton bertulang sekaligus berfungsi sebagai dinding penahan tanah (retaining wall). Kualitas beton menggunakan ready mix dengan mutu K-350 kedap air, untuk mengantiisipasi agar dinding nantinya tidak lembab dan mencegah rembesan air tanah masuk ke bangunan.

Pondasi telapak menggunakan bor file karena kondisi tanah berada di pinggir sungai yang rawan tergerus air dan cenderung tidak stabil sesuai dengan hasil penyelidikan kondisi tanah eksistiing.

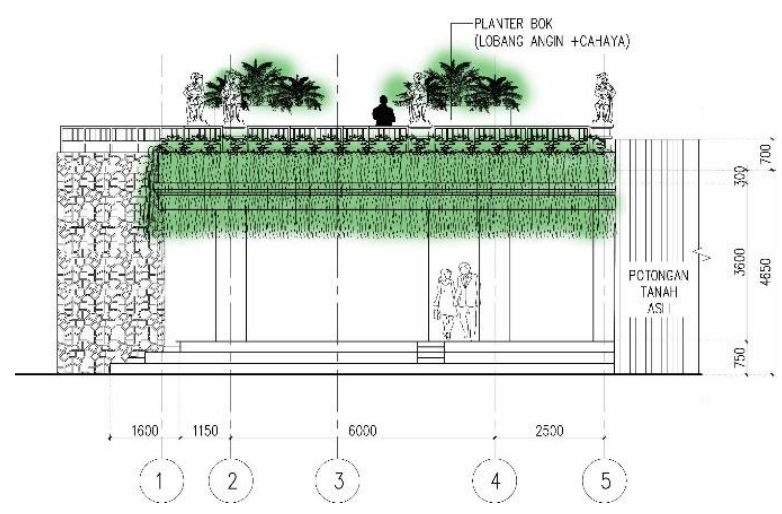

Gambar 9. Tampak Timur

sebagai posisi nista atau servis. Dalam penataan sentra kuliner ini toilet umum yang merupakan area servis ditempatkan di sisi barat yaitu di zona nista. Sedangkan untuk sentra kuliner ditempatkan pada posisi madya dan utama yaitu di sisi tengah dan timur.

Secara vertikal bangunan tradisional Bali mencerminkan sosok tubuh manusia (Tri Angga) yang memiliki bagian-bagian kepala berbentuk atap, badan berbentuk dinding atau tiang, dan kaki berbentuk lantai atau pondasi atau platform yang memiliki ciri-ciri identitas Bali. Dalam perancangan sentra kuliner ini, kaki adalah dasar dan lantai bangunan, badan disimbolkan dengan 
kolom kolom struktur bangunan, dan kepala adalah tembok railing beton dan tonjolan kantilever (shading device). Kantilever dengan panjang 1,5m untuk mengantisipasi tempais hujan dan radiasi sinar matahari agar tidak berlebihan.

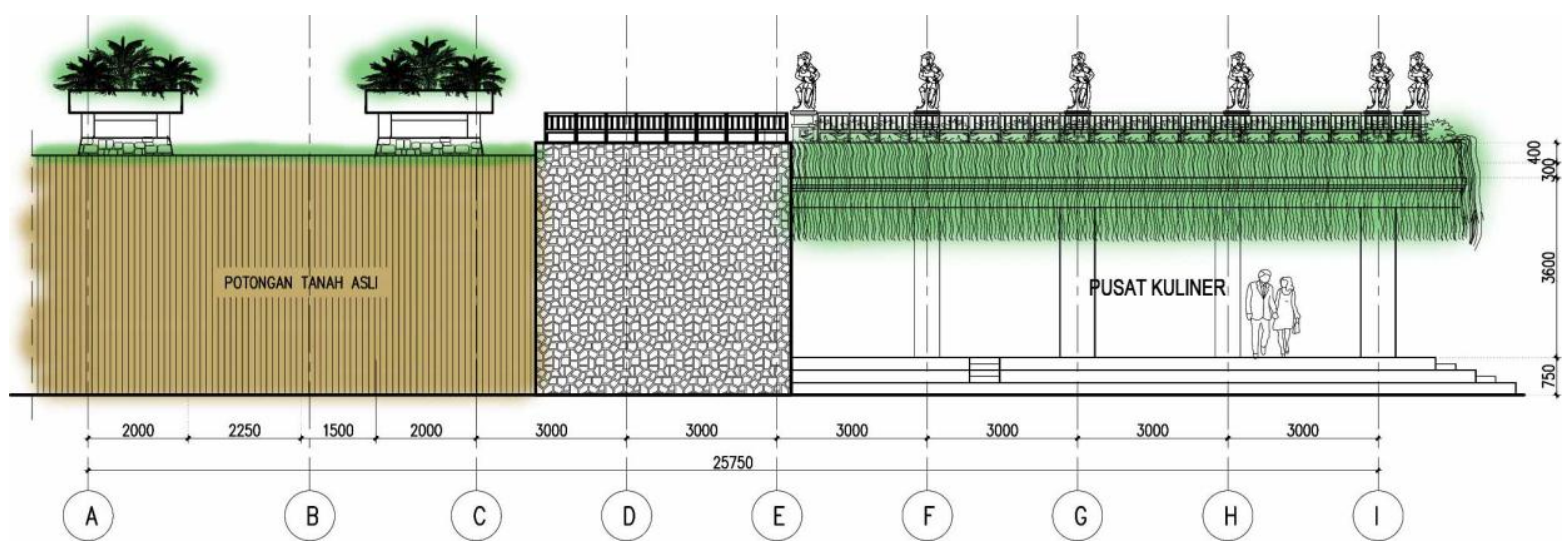

Gambar 10. Tampak Selatan

Analisa Dan Konsep Pencahayaan Dan Penghawaan Alami

Selaras dengan issue global tentang penanggulangan pemanasan global (global warming), desain bangunan agar menerapkan prinsip green building, yaitu semaksimal mungkin menggunakan pencahayaan dan penghawaan alami. Bali terletak di daerah tropis yang mendapat penyinaran matahari sepanjang tahun.

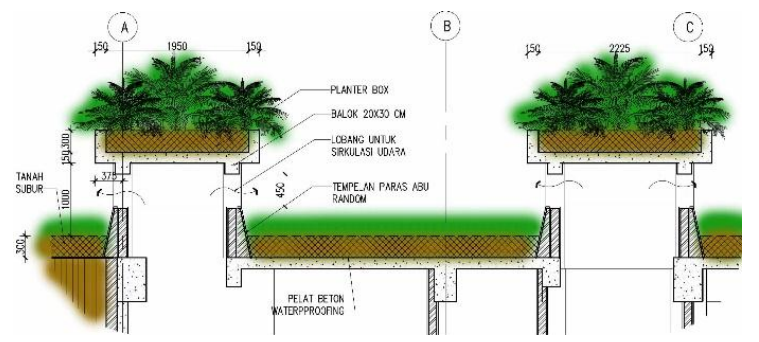

Gambar 11. Detail Planter Box Untuk Pencahayaan Dan Penghawaan Alami

Untuk pencahayaan dan penghawaan sentra kuliner ini menerapkan pencahayaan dan penghawaan alami. Area toilet umum tidak bisa mendapat pencahayaan dan penghawaan alami dari samping karena dikelilingi oleh tanah pada posisi basement. Sehingga pencahayaan dan penghawaan alami ruangan dirancang dari atas, yaitu dengan memodifikasi pelat beton lantai atas dengan memberi lobang. Diatas lobang diberi penutup pelat beton sekaligus berfungsi sebagai planter box dan di isi vegetasi seperti terlihat dalam gambar 11 . Posisi lobang angin sebanyak 4 buah dirancang lokasinya dan disinkronisasi dengan tata ruang di bawahnya sehingga tetap harmonis secara keseluruhan dan memiliki privasi yang baik. Untuk area sentra kuliner pencahayaan dan penghawaan alami langsung dari samping karena berupa area terbuka.

\section{KESIMPULAN}

Sentra kuliner dan toilet umum adalah salah satu unsur penunjang dari taman kota. Keberadaannya merupakan daya tarik tersendiri bagi taman kota sehingga keberadaannya perlu dilestarikan dan ditata supaya menjadi unsur penunjang positif bagi taman kota itu sendiri. Penataan sentra kuliner dan toilet umum sesuai dengan kebijakan pemerintah kota dan dengan memanfaatkan potensi site yang ada.

- Massa bangunan berupa bangunan tunggal dimana bagian atasnya berupa pelat beton yang di isi tanah subur dan dijadikan kebun /taman untuk mendukung fungsi utama taman kota. Sentra kuliner dan toilet umum dipindahkan ke lantai bawah.

- Perencanaan bangunan tetap menerapkan Arsitektur Tradisional Bali yaitu konsep sanga mandala dalam penzoningan dan penataan ruang, serta konsep tri angga (kepala, badan, dan kaki) dalam wujud dan tampilan bangunan.

- Pencahayaan dan penghawaan alami tetap diterapkan semaksimal mungkin walaupun pada posisi yang sulit, yaitu dibuka keatas yang posisinya disesuaikan dengan tata 
ruang dengan tetap mempertimbangkan estetika.

- Struktur direncanakan dengan baik agar awet dan berfungsi maksimal. Dinding yang berbatasan dengan tanah menggunakan beton bertulang untuk mengantisipasi rembesan air tanah. Dan pondasi telapak menggunakan bor pile untuk kestabilan bangunan karena berada di tepi sungai.

\section{DAFTAR PUSTAKA}

Juniastra, I. M. (2019). Re-Design Homestay Lokal Selaras Dengan Industri Pariwisata. Jurnal Ilmiah Vastuwidya, 2(2), 40-51.
Eko Budiharjo. 1997. Arsitektur Dan Kota Indonesia. Penerbit Alumni.

Gulo, A. A., Aritonang, E. R., \& Naibaho, P. (2018). Usulan Penataan Pedagang Kaki Lima di Kawasan Lapangan Merdeka Medan. Jurnal Arsitektur ALUR-Vol, 1(2).

Pemerintah Kota Denpasar Dinas Perumahan Kawasan Permukiman Dan Pertanahan. (2019). DED Penataan Toilet, Tempat Kuliner, Pos Jaga Taman-Taman Di Kota Denpasar.

Juniastra, I. M. (2021). Perkembangan Arsitektur Bale Banjar Ditinjau dari Fungsi dan Pelestarian Budaya Bali. Sinektika: Jurnal Arsitektur, 18(1), 36-45. 